\title{
THE EFFECT OF PARENTAL ATTENTION ON MATHEMATICS LEARNING OUTCOMES TO FIFTH GRADE STUDENTS OF PUBLIC ELEMENTARY SCHOOLS IN KEBUMEN SUB-DISTRICT IN ACADEMIC YEAR OF 2019/2020
}

\author{
Noviyanto Masruron', Ngatman², Joharman ${ }^{3}$ \\ Sebelas Maret University \\ noviyantomasruron27@gmail.com
}

\section{Article History}

accepted 01/10/2020

approved 01/11/2020

published 01/12/2020

\begin{abstract}
The study aimed to determine the effect of parental attention on student mathematics learning outcomes and to determine the contribution of parental attention on mathematics learning outcomes to fifth grade students of public elementary schools in Kebumen sub-districts in academic year of 2019/2020. It was quantitative correlational method. The prerequisite analysis test used normality and linearity. Data analysis used simple correlation test and significance level. The result showed that there was positive and significant correlation between parental attention and mathematics learning outcomes. The correlation level was moderate (0.248). Parental attention contributed $8.1 \%$ on mathematics learning outcomes. It concludes that there is positive and significant correlation between parental attention and mathematics learning outcomes to fifth grade students of public elementary schools in Kebumen sub-district in academic year of 2019/2020.
\end{abstract}

Keywords: parental attention, mathematics learning outcomes

\begin{abstract}
Abstrak
Penelitian ini bertujuan untuk mengetahui pengaruh antara perhatian orang tua terhadap hasil belajar matematika dan untuk menemukan seberapa besar tingkat perhatian orang tua terhadap hasil belajar matematika siswa kelas V SDN seKecamatan Kebumen tahun ajaran 2019/2020. Penelitian ini merupakan penelitian kuantitatif dengan metode korelasi. Uji prasyarat menggunakan uji normalitas dan linieritas. Analisis data dalam penelitian inii yaitu uji korelasi sederhana dan sumbangan efektif (SE). Penelitian in menghasilkan kesimpulan bahwa terdapat korelasi positif yang signifikan antara perhatian orang tua dan hasil belajar matematika siswa dengan tingkat korelasi sedang yaitu 0,248 dan sumbangan variabel perhatian orang tua terhadap hasil belajar matematika siswa yaitu $8,1 \%$. Berdasarkan hasil penelitian tersebut dapat disimpulkan bahwa terdapat korelasi positif yang signifikan antara perhatian orang tua dan hasil belajar matematika siswa kelas V SDN seKecamatan Kebumen tahun ajaran 2019/2020.
\end{abstract}

Kata kunci: Perhatian Orang Tua, Hasil Belajar, Matematika 


\section{Pendahuluan}

Pendidikan merupakan suatu usaha yang bersifat membimbing, yang dilakukan secara sadar oleh pendidik (termasuk orang tua) terhadap peserta didik dengan tujuan untuk mengembangkan potensi peserta didik agar terbentuk kepribadian yang sempurna (insan kamil) (Marimba dalam Juwantara: 28).. Pendidikan memiliki peran yang penting dalam mencerdaskan kehidupan bangsa serta pembangunan nasional sehingga menciptakan generasi yang berbudi luhur. Untuk mencapai tujuan dari mencerdaskan kehidupan bangsa tersebut dapat dicapai dengan meningkatkan kualitas pendidikan, salah satunya dengan pencapaian hasil belajar siswa. Salah satu faktor yang memengaruhi hasil belajar siswa yaitu perhatian orang tua.

Perhatian merupakan kegiatan yang dilakukan seseorang dalam suatu hubungan dengan pemilihan rangsangan yang datang dari lingkungannya (Slameto, 2010: 105). Selanjutnya, menurut Walgito (2010: 101) menyatakan bahwa perhatian merupakan pemusatan atau konsentrasi dari seluruh aktivitas yang ditunjukkan pada suatu kelompok atau objek.

Perhatian merupakan suatu kegiatan yang dilakukan dengan menfokuskan pada sebuah hal yang menciptakan ketertarikan serta memberikan dukungan. Dalam pendidikan, perhatian orang tua adalah fokus orang tua kepada anaknya yang menimbulkan bertambahnya aktivitas yang ditujukan pada anaknya baik kebutuhan fisik maupun non fisik yang bisa mendukung kualitas pendidikan anaknya.

Bentuk-bentuk perhatian orang tua kepada anaknya yaitu : (1) mendiskusikan kebutuhan anaknya; (2) mengatur waktu belajar anak; (3) menyediakan atau melengkapi alat belajar; (4) menciptakan hubungan anggota keluarga yang baik; (5) menciptakan suasana rumah yang tenang dan tentram; (6) pengertian orang tua; dan (7) latar belakang kebudayaan orang tua (Slameto, 2010: 33). Dari beberapa bentuk tersebut, orangtua diharapkan peka terhadap kebutuhan anaknya sehari-hari dengan tidak hanya memenuhi kebutuhan sehari-hari dalam kelangsungan hidupnya. Anak membutuhkan perhatian yang lebih efisien baik di dalam pendidikan formal maupun pendidikan non formal. Keberhasilan seorang anak dalam mencapai hasil belajar yang baik dan memuaskan, tidak semata-mata hanya mendapatkan perhatian dan tanggung jawab dari pihak sekolah, melainkan dari pihak keluarga (orangtua) yang juga memiliki tanggung jawab terhadap keberhasilan belajar anaknya.

Hasil belajar menurut Nawawi dapat diartikan sebagai tingkat keberhasilan siswa dalam mempelajari materi pelajaran di sekolah yang dinyatakan dalam skor yang diperoleh dari hasil tes mengenal sejumlah materi pelajaran tertentu (Susanto, 2016: 5). Hasil belajar adalah kemampuan dan keterampilan yang dimiliki siswa setelah siswa tersebut menerima sebuah pengalaman belajarnya (Sudjana, 2013: 22). (Taurina, 2015) mengatakan "Learning outcomes are described as written statements of what a learner is expected to know, understand and/or be able to do at the end of a period of learning", yang berarti hasil belajar merupakan pernyataan tentang apa yang diharapkan dapat diketahui siswa pada akhir pembelajaran. Dalam hal ini, untuk mengetahui kemana kemajuan hasil belajar yang telah dicapai oleh peserta didik, maka evaluasi harus dilakukan agar bisa diketahui tinggi-rendahnya hasil belajar peserta didik.

Perhatian orang tua merupakan salah satu faktor dari luar yang dapat mempengaruhi hasil belajar seorang anak, salah satunya dalam mata pelajaran matematika. Menurut Susanto (2016: 185) menjelaskan bahwa matematika adalah disiplin ilmu yang dapat meningkatkan kemampuan dalam berpikir, berargumentasi, memberikan sokongan dalam penyelesaian masalah dalam kehidupan sehari-hari, serta mendukung perkembangan ilmu pengetahuan dan teknologi. Maka dari itu, perhatian orang tua dalam mendorong keberlangsungan pendidikan anaknya 
kuhsusnya dalam mata pelajaran matematika perlu diperhatikan agar hasil belajar menjadi lebih baik.

Berdasarkan uraian di atas, penting kiranya dilakukan penelitian untuk mengetahui ada tidaknya pengaruh antara perhatian orang tua dengan hasil belajar matematika dan menghitung besarnya sumbangan perhatian orang tua terhadap hasil belajar matematika siswa kelas V SD di Kecamatan Kebumen melalui penelitian kuantitatif dengan judul "Pengaruh Perhatian Orang Tua terhadap Hasil Belajar Matematika Siswa Kelas V SDN Se-Kecamatan Kebumen Tahun Ajaran 2019/2020".

Tujuan penelitian ini adalah: (1) untuk mengetahui pengaruh antara perhatian orang tua terhadap hasil belajar matematika siswa kelas V SDN se-Kecamatan Kebumen tahun 2010/2020; (2) untuk menemukan seberapa besar tingkat perhatian orang tua terhadap hasil belajar matematika siswa kelas V SDN se-Kecamatan Kebumen tahun 2019/2020.

\section{Metode}

Penelitian ini merupakan penelitian kuantitatif dengan metode korelasi. Populasi penelitian ini adalah seluruh siswa kelas V di 59 SDN se-Kecamatan Kebumen tahun ajaran 2019/2020 dengan jumlah 1.598 siswa. Sampel dalam penelitian ini berjumlah 347 siswa kelas $V$ di dua belas SDN se-Kecamatan Kebumen yang dipilih secara acak dengan teknik cluster random sampling. Pengambilan sampel dengan cara cluster random sampling adalah melakukan randomisasi terdapat kelompok (sekolah), bukan terhadap subjek secara individu. Sekolah yang menjadi sampel dalam penelitian ini yaitu SDN 1 KEBUMEN, SDN 2 KEBUMEN, SDN 5 KEBUMEN, SDN 7 KEBUMEN, SDN 3 TAMANWINANGUN, SDN 4 TAMANWINANGUN, SDN 1 KARANGSARI, SDN 2 KARANGSARI, SDN 1 TANAHSARI, SDN 5 KUTOSARI, SDN ARGOPENI dan SDN GESIKAN.

Ada beberapa teknik pengumpulan data dalam kegiatan penelitian, seperti: tes, kuesioner, interviu, dan dokumentasi (Arikunto, 2010). Teknik pengumpulan data pada penelitian ini menggunakan angket dan ujian (tes). Angket digunakan untuk mengumpulkan data penelitian pada variabel bebas yaitu perhatian orang tua, sedangkan ujian (tes) digunakan untuk mengumpulkan data penelitian pada variabel terikat yaitu hasil belajar matematika. Sebelum digunakan, angket dan tes diuji validitasnya terlebih dahulu. Pengujian dilakukan di dua SDN di Kecamatan Kebumen diluar dari SD yang telah ditentukan menjadi sampel. Berdasarkan uji validitas angket uji coba perhatian orang tua, dari 58 butir angket yang diujikan terdapat 11 butir angket yang tidak valid dan 47 butir angket yang valid. Selanjutnya, uji validitas instrumen uji coba tes hasil belajar matematika siswa, dari 40 soal matematika yang diujikan, terdapat 15 soal yang tidak valid dan 25 soal yang valid.

Sebelum dilakukan uji prasyarat analisis data, hasil data yang diperoleh dari angket perhatian orang tua masih berupa data ordinal, maka harus diubah menjadi data interval. Untuk mengubah data ordinal ke data interval, peneliti menggunakan bantuan MS. Excel add-ins for statistics. Setelah diubah ke data interval, maka hasil penelitian dapat dilakukan uji prasyarat. Uji prasyarat analisis data yang digunakan yaitu normalitas dan uji linieritas. Analisis data yang digunakan yaitu uji korelasi sederhana dan sumbengen efektif (SE) dengan taraf signifikansi 5\%.

\section{Hasil dan Pembahasan}

Penelitian ini dilakukan dengan memberikan angket perhatian orang tua dan tes hasil belajar matematika kepada dan siswa kelasV di dua belas SDN di Kecamatan Kebumen. Angket ini berisi pernyataan-pernyataan yang memuat indikator perhatian orang tua dan tes hasil belajar berisi pertanyaan yang mewakili materi matematika kelas $\mathrm{V}$, sehingga diperoleh data yang dapat mengukur tinggi rendahnya perhatian 
orang tua dan hasil belajar matematika. Prasyarat data terpenuhi yaitu data berasal dari populasi berdistribusi normal dan terdapat hubungan linear antara perhatian orang tua dan hasil belajar matematika.

Hasil uji normalitas sebaran terhadap variabel perhatian orang tua menghasilkan nilai $p$-value sebesar 0,200 (sig > 0,05). Hasil uji berdasarkan kaidah menunjukkan variabel perhatian orang tua adalah normal. Hasil uji normalitas sebaran terhadap variabel hasil belajar matematika menghasilkan nilai $p$-value sebesar 0,054 (sig > 0,05). Hasil uji berdasarkan kaidah menunjukkan variabel hasil belajar matematika adalah normal

Data dikatakan terdapat hubungan linear antara vai=riabel $X$ dan $Y$ jika $p$ value Deviation from Linearity $>0,05$. Nilai $p$ value Deviation from Linearity yaitu $0,191>0,05$ sehingga terdapat hubungan linear antara hasil belajar matematika dan perhatian orang tua.

Korelasi antara hasil belajar matematika dan perhatian orang tua diuji menggunakan uji korelasi pearson product moment. Uji korelasi menggunakan bantuan SPSS versi 23.

Hipotesis yang digunakan adalah $\mathrm{H}_{0}=$ tidak ada hubungan antara perhatian orang tua dan hasil belajar matematika dan $\mathrm{H}_{1}=$ ada hubungan antara perhatian orang tua dan hasil belajar matematika.

Tabel 1 Hasil Analisis Korelasi Perhatian Orang Tua dengan Hasil Belajar Matematika

\begin{tabular}{llll}
\hline Correlations & \multicolumn{2}{l}{} & \\
\hline \multicolumn{2}{c}{ PerhatianOrang } & PerhatianOrangTua & HasilBelajar \\
\cline { 2 - 4 } Tua & Pearson Correlation & 1 & $.284^{* *}$ \\
\cline { 2 - 4 } & Sig. (1-tailed) & .000 \\
\cline { 2 - 4 } & $\mathrm{N}$ & 322 & 322 \\
\hline HasilBelajar & Pearson Correlation & $.284^{* *}$ & 1 \\
\cline { 2 - 4 } Matematika & Sig. (1-tailed) & .000 & 322 \\
\cline { 2 - 4 } & $\mathrm{N}$ & 322 & \\
\hline
\end{tabular}

**. Correlation is significant at the 0.01 level (1-tailed).

Berdasarkan analisis data menggunakan uji korelasi pearson product moment, diketahui bahwa terdapat hubungan yang signifikan antara perhatian orang tua dengan hasil belajar matematika siswa kelas $\mathrm{V}$ dengan koefisien korelasi sebesar 0,284 dan Sig. (1-tailed) yaitu 0,000 ( $p$ value $<0,05$ ). Nilai 0,05 adalah taraf signifikansi yang digunakan pada penelitian ini. Sesuai dengan hasil uji korelasi tersebut, maka hipotesis yang menyatakan bahwa terdapat hubungan yang positif dan signifikan antara perhatian orang tua dan hasil belajar matematika siswa kelas V SDN se-Kecamatan Kebumen tahun ajaran 2019/2020 dapat diterima. Hasil analisis koefisien korelasi antara variabel perhatian orang tua dan hasil belajar matematika yaitu 0,284.

Sesuai hasil perhitungan sumbangan perhatian orang tua terhadap hasil belajar matematika siswa sebesar $8,1 \%$ dan sisanya sebesar $91,9 \%$ dipengaruhi oleh faktor lain. Hal ini sesuai dengan pendapat Munib, dkk (Sulistyanto, $2016: 129$ ) bahwa orang tua atau pengganti orang tua yang menjadi pendidik dalam keluarga. 
Berdasarkan penelitian dan perhitungan yang telah dilakukan, dapat diketahui bahwa perhatian orang tua memiliki hubungan yang positif dengan hasil belajar matematika. Oleh karena itu, dapat dikatakan bahwa semakin tinggi perhatian orang tua maka semakin tinggi pula hasil belajar matematika siswa. Begitu pula sebaliknya, semakin rendah perhatian orang tua maka akan semakin rendah pula hasil belajar matematika siswa.

Hasil penelitian ini sesuai dengan penelitian yang dilakukan oleh Handayani (2017: 136) yang menyatakan bahwa terdapat pengaruh positif perhatian orang tua terhadap hasil belajar matematika di SDN Wilayah binaan Kelurahan Duren Sawit, Jakarta Timur, dengan nilai koefisien korelasi sebesar 0,746. Perbedaan penelitian yang dilakukan oleh Handayani dengan penelitian yang dilakukan oleh peneliti terletak pada kelas yang diteliti. Pada penelitian Handayani dilakukan di kelas VI SD, sedangkan penelitian ini dilakukan di kelas V SD. Penelitian lain yang dilakukan pada kelas IV SD Negeri Kembangarum 2 Mranggen juga mengungkapkan bahwa perhatian orang tua berhubungan positif terhadap hasil belajar siswa dengan nilai product moment sebesar 0,564 (Soegeng dan Nisa, 2014: 7). Sedangkan penelitian yang dilakukan oleh Soegeng dan Nisa dengan penelitian yang dilakukan oleh peneliti adalah pada jumlah subjek penelitian, penelitian Soegeng dan Nisa hanya dilakukan di $1 \mathrm{SD}$, sementara penelitian in dilakukan di 1 Kecamatan.

Hasil perhitungan sumbangan efektif pada variabel perhatian orang tua dan hasil belajar matematika siswa didapatkan hasil sebesar $8,1 \%$, artinya perhatian orang tua dapat berperan dalam meningkatkan hasil belajar matematika siswa yaitu sebesar $8,1 \%$ dan sisanya sebesar $91,9 \%$ dipengaruhi oleh faktor lain seperti faktor fisik, faktor psikis, faktor sekolah, dan faktor lingkungan.

Berdasarkan uraian di atas, dapat disimpulkan bahwa hasil penelitian ini telah sesuai dengan teori yang ada dan didukung pula dengan penelitian yang relevan, maka hasil penelitian ini adalah ada korelasi positif dan signifikan antara perhatian orang tua dengan hasil belajar matematika siswa kelas V SDN se-Kecamatan Kebumen tahun ajaran 2019/2020.

\section{Simpulan}

Berdasarkan hasil penelitian dan pembahasan yang telah diuraikan, maka dapat disimpulkan bahwa: (1) perhatian orang tua memiliki hubungan yang positif dan signifikan dengan hasil belajar matematika siswa kelas V SD Negeri se-Kecamatan Kebumen dengan tingkat korelasi sedang yaitu 0,284 ; (2) besar sumbangan variabel perhatian orang tua terhadap hasil belajar matematika siswa yaitu $8,1 \%$.

Berdasarkan simpulan yang telah dipaparkan, peneliti memberikan beberapa saran: (1) bagi guru; (2) bagi sekolah, pihak sekolah hendaknya mampu memberikan pengertian kepada orang tua siswa mengenai perhatian orang tua pada hasil belajar maatematika siswa sehingga siswa mampu mendapatkan hasil belajar matematika yang tinggi; (3) bagi peneliti selanjutnya yang ingin melakukan penelitian yang hamir sama tentang pengaruh perhatian orang tua dengan hasil belajar matematika siswa dapat menjadi acuan dalam penelitian korelasi dan mencari sumber referensi lainnya sehingga mampu melakukan penelitian yang lebih baik.

\section{Daftar Pustaka}

Arikunto, S. (2010). Prosedur Penelitian Suatu Pendekatan Praktik. Jakarta: Rineka Cipta.

Handayani, Dian. (2017). Pengaruh Perhatian Orang Tua dan Konsep Diri Siswa terhadap Hasil Belajar Matematika Siswa. Jurnal Pendidikan Dasar Vol 8, Edisi 1, 127-143. 
Juwantara, R.A (2019). Analisis Teori Perkembangan Kognitif Piaget Pada Tahap Anak Usia Operasional Konkret 7-12 Tahun Dalam Pembelajaran Matematika. Jurnal IImiah Pendidikan Guru Madrasah Ibtidaiyah. Vol. 9, No. 1 (Juni 2019), Hal. $27-34$

Slameto. (2010). Belajar dan Faktor-faktor yang Mempengaruhi. Jakarta: Rineka Cipta.

Soegeng, A.Y \& Nisa, Zahrotun. (2014). Hubungan antara Perhatian Orang Tua dan Hasil Belajar pada Pembelajaran Tematik Integratif Siswa Kelas IV SD Negeri Kembangarum 2 Mrangen Demak. Jurnal Universitas PGRI Semarang Vol 4, No 2.

Sudjana, N. (2013) Penilaian Hasil Belajar Mengajar. Bandung : PT. Remaja Rosdakarya.

Susanto, A. (2016). Teori Belajar dan Pembelajaran di Sekolah Dasar. Jakarta: Prenadamedia Group

Sulistyanto, D. F. (2016). Pengaruh Kedisiplinan dan Perhatian Orang Tua terhadap Prestasi Belajar Siswa Kelas V Sekolah Dasar Se-Dabin I Kecamatan Pituruh Kabupaten Purworejo. Skripsi tidak dipublikasikan. Universitas Negeri Semarang.

Taurina, Z. (2015). Student's Motivation and Learning Outcomes: Significant Factor in Internal Study Quality Assurance System. International Journal for CrossDisciplinary Subjects in Education (IJCDSE), Special Issue Volume 5 Issue 4: 2526-2630.

Walgito, Bimo. (2010). Pengantar Psikologi Umum. Yogyakarta: C.V Andi Offset. 